\title{
MANAGEMENT OF INFANTS LESS THAN SIX MONTHS WITH SEVERE ACUTE MALNUTRITION (SAM).
}

1. MD (Pediatrics)

Assistant Professor Preventive

Pediatrics

$\mathrm{CH} \& \mathrm{ICH}$, Multan.

2. FCPS (Pediatrics)

Senior Registrar Pediatrics The Children Hospital \& ICH Multan.

3. MBBS, DCH, FCPS

Associate Professor

Children Hospital Multan.

4. M.Sc (Food and Nutrition)

Research Associate

Aga Khan University, Karachi.

5. MBBS, MPH

SMO Pediatrics

Pepsico International, Multan.

6. BSc (Hons.) Human Nutrition and Dietetics

Nutritionist Student

Baho Din Zikria University, Multan.

Correspondence Address:

Reema Arshad

House No. 69A

Buch Exective Block, Multan.

reemaarshad0@gmail.com

Article received on:

06/03/2019

Accepted for publication:

$10 / 10 / 2019$

\begin{abstract}
Saadia Khan', Gul Hasan ${ }^{2}$, Ibad $\mathrm{Ali}^{3}$, Reema Arshad ${ }^{4}$, Imrana Ali5 ${ }^{5}$ Asad Abbas ${ }^{6}$
\end{abstract}
ABSTRACT... Objectives: To determine the average weight gain after lactation counseling therapy in infants up to six months of age having severe acute malnutrition. Study Design: Quasi experimental trial. Setting: Stabilization Center Unit, the Children's Hospital \& the Institute of Child Health, Multan. Period: $1^{\text {st }}$ October 2015 to $1^{\text {st }}$ October 2016. Material \& Methods: A total of 205 children with SAM were included in this study using non-probability consecutive sampling technique. Mothers of these children were motivated for more than 8 feeds/day, positioning and attachment at breast feeding was advised, demonstrated and monitored. Results: Of these 205 study cases, 142 (69.3\%) were boys and 63 (30.75) were girls. Mean age of our study cases was $3.75 \pm 1.39$ months (with minimum age of our study cases was 2 months while maximum age was 6 months). Of these 205 study cases, 101 (49.3\%) were from rural areas while $104(50.7 \%)$ were from urban areas. Mothers of $117(57.1 \%)$ study cases were literate while 88 (42.9\%) were illiterate. Majority of our study cases i.e. $129(62.9 \%)$ were from middle income background and $76(37.1 \%)$ were from poor social background. Partial breast feeding was positive in 145 (70.7\%) of our study cases and no breast feeding was noted in 60 (29.3\%). Mean baseline weight was $2737.07 \pm 585.60$ grams. Mean weight at discharge was $2995.37 \pm 621.97$ grams and mean weight gain was $800.0 \pm 258.29$ grams. Average daily weight gain was noted to be $11.27 \pm 4.73 \mathrm{~g} / \mathrm{kg} /$ day. Conclusion: Our study results have shown that lactation counseling therapy significantly improves weight gain in children under 6 months of age with severe acute malnutrition. Mothers of infants presenting with malnutrition must be counselled to breast feed to improve their clinical outcomes. Mean weight gain was significantly associated with maternal education and socioeconomic status. Further studies are suggested from different parts of the country to generate our local data at national level which may be incorporated for national health policy guidelines.

Key words: Counseling, Lactation, Severe Acute Malnutrition.

Article Citation: Khan S, Hasan G, Ali I, Arshad R, Ali I, Abbas A. Management of infants less than six months with SAM (Severe Acute Malnutrition). Professional Med J 2020; 27(6):1113-1118. DOI: 10.29309/TPMJ/2020.27.06.3386

\section{INTRODUCTION}

The term malnutrition encompasses both ends of the nutrition spectrum, from under nutrition (underweight, stunting, wasting, and micronutrient deficiencies) to overweight. ${ }^{1}$ Adequate nutrition is essential in early childhood to ensure healthy growth, proper organ formation and function, a strong immune system, and neurological and cognitive development. ${ }^{2}$ Malnutrition has been proven as one of the strongest risk factors in child mortality, and is responsible for more than $50 \%$ of under-five deaths in the developing countries. ${ }^{3}$ The reduction of infant and young child malnutrition is essential to decrease the infant and child mortality and the achievement of the Millennium Development Goals (MDGs). In 2001, the World Health Organization announced that infants should be exclusively breast fed for six months. ${ }^{4}$ Importance of exclusive breastfeeding for essential growth and development of infants and young children is accepted globally. ${ }^{5}$ About $22 \%$ of the newborn deaths could be prevented if breastfeeding is initiated within first hour after birth and $16 \%$ if breastfeeding is started within first 24 hours. $^{6}$ Infants who are not breastfed are 15 times more likely to die from pneumonia and 11 times more likely to die of diarrhea as compared to those who are breastfed exclusively. ${ }^{7}$ Over the last 10 years, significant progress has been made improving the management of malnourished 
children through the development of Community Management of Acute Malnutrition (CMAM). However, there are no significant researches on SAM outcome in infants and under 6 months children. This has been acknowledged by the MAMI (management of acute malnutrition) project in Pakistan. ${ }^{8}$ Over the last decade there is an increase in early initiation of breastfeeding but overall breast feeding rates are declining and bottle feeding prevalence has increased upto 34 $\%{ }^{9}$

In another study conducted in India, 431 children suffering from severe acute malnutrition were admitted and out of that 108 children were below 6 months. more than one third of these cases were managed and improved by correct positioning of breastfeeding and attachment. The average weight gain of these children was $12 \pm 9.73 \mathrm{~g} / \mathrm{kg} / \mathrm{d} .^{10}$

The rationale of this study is to find out the average weight gain in children suffering from severe acute malnutrition, below six months of age after lactation counseling therapy. In Pakistan previously there are no researches that determines lactation counselling therapy results in children suffering from SAM. So we planned to conduct this study to find the role of lactation counseling therapy in infants admitted at NRC, $\mathrm{CHC}$ Multan. This will help us to improve our current knowledge and practice and in future we can revise strategies for counseling of mothers to promote breast feeding in order to prevent severe acute malnutrition in infants.

\section{OBJECTIVE}

To determine the average weight gain after lactation counseling therapy in infants up to six months of age having severe acute malnutrition.

\section{OPERATIONAL DEFINITION}

- Severe acute malnutrition (SAM) according to WHO classification: SAM is defined as weight for length (WFL) z score < -3 SD.

- Lactation counseling therapy mothers were motivated for more than 8 feeds/day, positioning and attachment at breast feeding was advised, demonstrated and monitored.
- Weight gain it was measured in terms of difference in final weight of baby from baseline in terms of gram $/ \mathrm{kg} /$ day after start of lactation during hospital stay. Weight gain more than $5 \mathrm{gm} / \mathrm{kg} /$ day will be considered satisfactory.

- Positioning baby neck should be straight or bent slightly back and should be close to mother, whole baby supported and face towards breast with nose opposite the nipple.

- Exclusive breast feeding no food or liquid other than breast milk, not even water was given to infant from birth.

- Partial breast feeding breast milk plus three or more feed of any food or liquid including non-human milk during the past 7 days.

- Literate anybody who has the ability to read and write

\section{MATERIAL \& METHODS}

This was a Quasi experimental trial, conducted at Stabilization Center Unit, the Children's Hospital $\&$ the Institute of Child Health, Multan.

The Duration of Study was 1 year after approval of synopsis from $1^{\text {st }}$ October 2015 to $3^{1 \text { st }}$ March 2016.

Sample size of 205 cases is calculated with $95 \%$ Confidence level, $1 \%$ margin of error and taking magnitude of average weight gain i.e. 12.1 7.3g/ $\mathrm{kg} /$ day in children $<6$ months of age underwent lactation counseling therapy for management of SAM.

For sampling Non-probability consecutive sampling was used.

Inclusion Criteria

Infants 0-6 month of age of either gender with initial weight <-3 SD weight for length.

Infants with exclusive, partial and no breast feeding.

\section{Exclusion Criteria}

Critically sick infants requiring Intensive care (on clinical evaluation).

Major congenital malformations like skeletal, 
visceral, dysmorphism, cleft palate and lip. (on clinical examination).

Infants whose mothers cannot stay in the hospital at least for 14 days.

Study was started after taking permission from the institutional ethical committee. Two hundred and five infants, who fulfill the inclusion and exclusion criteria, were recruited in the study after stabilization phase from Nutritional Rehabilitation centre, $\mathrm{CH} \& \mathrm{ICH}$ (Children hospital and Institute of Child Health Multan). Informed consent was obtained from parents. Demographic details like name, age, gender and anthropometric measurements were obtained. The infant was weighed by using a SECA digital weighing scale (precision $5 \mathrm{~g}$ ) at baseline. Then mothers of all recruited infants were encouraged and counseled for breast feeding. Mothers were counseled for benefits of exclusive breast feeding, position/ attachment technique for feeding, hazards of bottle feed. The child was weighed daily and at discharge after 14 days of hospital stay to measure difference in weight from baseline (as per operational definition). All information was recorded on study proforma (attached).

All the data was entered and analyzed by using SPSS v-20. Mean and standard deviation were calculated for all variables like age, initial weight and final weight gain. Stratification was done for the following effect modifiers like age, breast feeding status on admission, education status of the mother and socioeconomic status. Frequency and percentage were calculated for gender of infant and breast feeding status. Final weight was subtracted from initial weight to measure weight gain of infants. Post stratification paired t-test was applied to measure the significance of weight gain. P-value $\leq 0.05$ was taken as significant.

\section{RESULTS}

Our study included a total of 205 children with severe acute malnutrition (SAM) meeting inclusion criteria of our study. Of these 205 study cases, 142 (69.3\%) were boys and 63 (30.75) were girls.
Mean age of our study cases was $3.75 \pm 1.39$ months (with minimum age of our study cases was 2 months while maximum age was 6 months). Mean age of boys was $3.68 \pm 1.30$ months while that of girls was $3.89 \pm 1.57$ months. $(p=0.330)$. The result of this study depicts that most of the samples i.e. 108 (52.7\%) belonged to the age group of $3-6$ months.

Of these 205 study cases, 101 (49.3\%) were from rural areas while 104 (50.7\%) were from urban areas. Mothers of $117(57.1 \%)$ study cases were literate while 88 (42.9\%) were illiterate. Majority of our study cases i.e. 129 (62.9\%) were from middle income background and 76 (37.1\%) were from poor social background. Partial breast feeding was positive in 60 (29.3\%) of our study cases and no breast feeding was noted in 145 (70.7\%). (Table No. 3 - 6)

Mean baseline weight was 2737.07 \pm 585.60 grams (with minimum baseline weight was 1400 grams while maximum was 4000 grams). Mean weight at discharge was $2995.37 \pm 621.97$ grams (with minimum weight at 1600 grams and maximum weight at discharge was 4100 grams) and mean weight gain was $800.0 \pm 258.29$ grams. Average daily weight gain was noted to be $11.27 \pm 4.73 \mathrm{~g} / \mathrm{kg} /$ day .

Weight gain was stratified with regards to gender, age, residential status, socioeconomic status, mother's educational status and breastfeeding status and $p$ values were found to be $p=0.064$, $p=0.515, p=0.699, p=0.001, p=0.005$ and $p=$ 0.999 respectively.

\begin{tabular}{|c|c|c|c|}
\hline \multirow{2}{*}{ Age Groups } & \multicolumn{2}{|c|}{ Weight gain } & \multirow{2}{*}{ P-Value } \\
\hline & Mean & SD & \\
\hline $\begin{array}{l}0-3 \text { Months } \\
(\mathrm{n}=97)\end{array}$ & 268.04 & 238.28 & \multirow{2}{*}{0.515} \\
\hline $\begin{array}{l}3-6 \text { months } \\
(n=108)\end{array}$ & 249.53 & 164.55 & \\
\hline
\end{tabular}




\begin{tabular}{|l|c|c|}
\hline $\begin{array}{c}\text { Breastfeeding } \\
\text { Status }\end{array}$ & Frequency & Percentage \\
\hline No feeding & 145 & $70.7 \%$ \\
\hline Partial feeding & 60 & $29.3 \%$ \\
\hline \multicolumn{2}{|c|}{ Table-II. Stratification of breastfeeding status } \\
(n= 205)
\end{tabular}

\section{DISCUSSION}

A child with SAM has a limited ability to respond to stressors (infection and environmental), is highly vulnerable, and has a high mortality risk. ${ }^{11}$ In children under 5 years of age Severe Acute Malnutrition and stunting are the major causes of mortality and DALY's. ${ }^{12}$ It is critical that such children are treated proactively with intensive treatment regimens of short duration, aiming to rehabilitate the child in a few weeks. ${ }^{13}$

Relatively little has been published on treatment outcomes for SAM in outpatient therapeutic program (OTP). One study in rural Niger demonstrative of children enrolled in an outpatient treatment programme for moderate acute malnutrition demonstrated that $80 \%$ recovered, $4 \%$ defaulted, and $0.4 \%$ died. In the same setting, $30 \%$ of children who completed treatment for moderate acute malnutrition either relapsed or died within one-year following treatment. ${ }^{14}$

Our study included a total of 205 children with severe acute malnutrition (SAM) meeting inclusion criteria of our study. Of these 205 study cases, 142 (69.3\%) were boys and 63 (30.75) were girls. This is in compliance with other studies who reported male gender predominance over female gender. ${ }^{15} \mathrm{~A}$ study conducted by Saaka et $\mathrm{al}^{16}$ reported with $54 \%$ male gender predominance which is similar to that of our study results.

Mean age of our study cases was $3.75 \pm 1.39$ months (with minimum age of our study cases was 2 months while maximum age was 6 months). Mean age of boys was $3.68 \pm 1.30$ months while that of girls was $3.89 \pm 1.57$ months. $(p=0.330)$. The results of this study shows that most of the cases i.e. $108(52.7 \%)$ belonged to the age group of $3-6$ months. Singh et al $^{10}$ reported $47(43.5 \%)$ infants were $<2$ months of age, 43 $(39.8 \%)$ infants were $2-4$ months and 18 (16.7\%) infants were $4-<6$ months of age. These findings of Singh et $\mathrm{al}^{10}$ are similar to that of our study results.

Of these 205 study cases, 101 (49.3\%) were from rural areas while $104(50.7 \%)$ were from urban areas. Similar results have been reported by Saaka et al. ${ }^{16}$ Mothers of $117(57.1 \%)$ study cases were literate while 88 (42.9\%) were illiterate. Jamro et al ${ }^{17}$ reported $66.7 \%$ illiteracy which is quite higher than our study results.

Majority of our study cases i.e. 129 (62.9\%) were from middle income background and 76 (37.1\%) were from poor social background. Similar findings have been reported by Jamro et al ${ }^{17}$ from Sukkur, Sindh.

Partial breast feeding was positive in 145 (70.7\%) of our study cases and no breast feeding was noted in 60 (29.3\%). Jamro et $\mathrm{al}^{17}$ from Sukkur, Sindh reported $62.9 \%$ partial breast feeding.

Data on lactation counseling therapy outcome is limited and one study is available from India which has highlighted the importance lactation counseling therapy in children with SAM. ${ }^{18}$ Mean baseline weight was $2737.07 \pm 585.60$ grams (with minimum baseline weight was 1400 grams while maximum was 4000 grams). Mean weight at discharge was $2995.37 \pm 621.97$ grams (with minimum weight at 1600 grams and maximum weight at discharge was 4100 grams) and mean weight gain was $800.0 \pm 258.29$ grams. Average daily weight gain was noted to be $11.27 \pm 4.73 \mathrm{~g} /$ $\mathrm{kg} /$ day. A similar study done in India ${ }^{10}$ reported 12 $\pm 9.73 \mathrm{~g} / \mathrm{kg} /$ day these results are in compliance with that of our study results.

\section{CONCLUSION}

Our study results have shown that lactation counseling therapy significantly improves weight gain in children under 6 months of age with severe acute malnutrition. Mothers of infants presenting with malnutrition must be stressed to breast feed to improve their clinical outcomes. Mean weight gain was significantly associated with maternal education and socioeconomic status. Further studies are suggested from different parts of the 
country to generate our at national level which may be incorporated for national health policy guidelines

Copyright $(10$ Oct, 2019.

\section{REFERENCES}

1. Alderman $\mathrm{H}$, Shekar M. Nutrition, Food security and health. In: Kliegman RM, Stanton BF, St. Geme III JW, Schor NF, Behrman RE. Nelson text of Pediatrics. Philadelphia, Pa: Elsevier Saunder; 2011: p.171.

2. World Health Organization. Levels and trends in child malnutrition. New York: UNICEF; 2012:p.4.

3. Schaible UE, Kaufnaann SH. Malnutrition and infection. Complex mechanisms and global impact. PLoS Med 2007; 4:e115.

4. World Health Organization (WHO). Infant and young child nutrition. 55th World Health Assembly. New York: WHO; 2002.

5. Gibney MJ1, Walsh M, Brennan L, Roche HM, German $B$, van Ommen B. Metabolomics in human nutrition: opportunities and challenges. Am J Clin Nutr 2005; 82(3):497-503.

6. Edmond KM, Zandoh C, Quigley MA, Amenga-Etego S, Owusu-Agyei S, Kirkwood BR. Delayed breast feeding initiation increases risk neonatal mortality. Pediatrics 2006; 7(3): e380-6.

7. Gupta GR. Tackling pneumonia and diarrhea; The deadliest diseases for the world's poor children. Lancet. 2012; 379(9832):2123-4.

8. Interagency steering group (IASG). Management of acute malnutrition in infants (MAMI) project. Technical Review: Current evidence, policies, practices \& programme outcomes. 2010.

9. Save The Children Program. Breastfeeding: A roadmap to promotion \& protection. Save the Children Pakistan Program. London: UK; 2013: p.20.
10. Singh D. Nutritional rehabilitation of children $<6$ months with severe acute malnutrition. 2014. http:// www.ennonline.net/fex/47/nutritional.

11. Bhutta ZA, Ahmed T, Black RE, Cousens S, Dewey $\mathrm{K}$, Giugliani $\mathrm{E}$, et al. What works? Interventions for maternal and child undernutrition and survival. Lancet. 2008; 371:417-40.

12. Guerrant RL, Oriá RB, Moore SR, Oriá MO, Lima AA. Malnutrition as an enteric infectious disease with long-term effects on child development. Nutr Rev. 2008; 66:487-505.

13. Caulfield LE, Richard SA, Black RE. Undernutrition as an underlying cause of malaria morbidity and mortality in children less than five years old. Am J Trop Med Hyg. 2004; 71:55-63.

14. Nackers F, Broillet F, Oumarou D, Djibo A, Gaboulaud $\mathrm{V}$, Guerin PJ, et al. Effectiveness of ready-to-use therapeutic food compared to a corn/soy-blendbased pre-mix for the treatment of childhood moderate acute malnutrition in Niger. J Trop Pediatr. 2010; 56:407-13.

15. BM, Mason JB. Proceedings of the WHO, UNICEF, and SCN informal consultation on community-based management of severe malnutrition in children. Food Nutr Bull. 2006; 27:S99-104.

16. Saaka $\mathrm{M}^{1}$, Osman $\mathrm{SM}^{2}$, Amponsem $\mathrm{A}^{3}$, Ziem $\mathrm{JB}^{3}$, AbdulMumin $A^{3}$, Akanbong $P^{3}$, et al. Treatment outcome of severe acute malnutrition cases at the tamale Teaching Hospital. J Nutr Metab. 2015; 2015:641784. doi: $10.1155 / 2015 / 641784$.

17. Jamro B, Junejo AA, Lal S, Bouk GR, Jamro S. Risk factors for severe acute malnutrition in children under the age of five year in Sukkur. Pak J Med Res. 2012; 51(4):111-3.

18. Golden $\mathrm{MH}$. Evolution of nutritional management of acute malnutrition. Indian Pediatr. 2010; 47:667-78. 


\section{AUTHORSHIP AND CONTRIBUTION DECLARATION}

\begin{tabular}{|c|c|c|c|}
\hline Sr. \# & Author(s) Full Name & Contribution to the paper & Author(s) Signature \\
\hline 1 & Saadia Khan & Proposal topic, Basic methodology. & \\
\hline 2 & Gul Hasan & $\begin{array}{l}\text { Data collection, Statics analysis, } \\
\text { Interpretation of resutls. }\end{array}$ & $\frac{9}{18}$ \\
\hline 3 & Ibad Ali & $\begin{array}{l}\text { Manuscript writing, References } \\
\text { citation. }\end{array}$ & sed \\
\hline 4 & Reema Arshad & $\begin{array}{l}\text { Manuscript writing, References } \\
\text { citation, Overall review. }\end{array}$ & 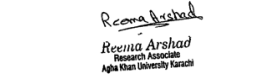 \\
\hline 5 & Imrana Ali & Quality insurer, review of literature. & . \\
\hline 6 & Asad Abbas & Data collection. & Acadtens \\
\hline
\end{tabular}

